\title{
Impact of Technology on Program and Institutional Assessment in Higher Education
}

\author{
Wang Chengxia \\ Foreign Languages College \\ North China Institute of Science and Technology \\ Yanjiao, East of Beijing \\ E-mail:tongtong1019@163.com
}

\begin{abstract}
This chapter explores the impact of technology on assessment and evaluation in higher education. The impacts on program and organizational assessment are discussed. Technology for organizational assessment has continued to boom in light of the dual push for both accountability and continuous improvement by accreditors. The social impacts and burden of organizational assessment and evaluation are discussed. Overall, it is concluded that in order to evaluate the impact of technology, attention needs to be paid to the consequences of organization assessment.
\end{abstract}

Keywords-impact; technology; program; assessment

\section{INTRODUCTION}

There is no question that new technologies for assessment and evaluation in higher education have impacted students, faculty, and administrators. It has created more options for creating assessments that can be used to improve student learning.

Additionally, it has created more efficient ways to assess more complex and authentic academic products like projects and portfolios that students can create. Further, new technologies have created new kinds of products that could be used as alter-natives for assessing students.

\section{IMPACT ON PROGRAM AND INSTITUTIONAL ASSESSMENT}

Technology has created an ability to implement assessment systems for continuous improvement and accountability purposes for institutions of higher learning. Generally there are three major purposes to assessment systems that are created for accreditation organizations. One is to help provide evidence that the organization meets the standards the agency sets for programs and institutions. A second is for public accountability purposes. Data collected for accreditation purposes is publicly shared so that policy makers, funders, and other stakeholders are aware of the successes or failures of organizations. Finally, a third reason for development of organizational assessment systems is for devising and setting up a system for continuous improvement of programs and the organization.

Students are often assessed in new or additional ways and sometimes required to purchase licensing for electronic portfolio software. The work that has focused on improvement has been driven by notions of the learning organization (Argyris, 1991, 2004). Some improvement systems are driven by business models like Six Sigma (e.g., see Murphy, 2009) and the Baldridge plan (Satterlee, 1996). Educational organizations use data driven systems to help their organizations better meet goals and serve their students.

Technology helps make the process of strategic planning and data collection easier. Software for strategic planning typically provides a data base for goals, evidence, and plans for improvement.

Such software helps organize cycles of planning, evaluating, and action. Departments, programs, colleges or other units within a college or university set goals and/or objectives, identify or create assessment data to determine whether the goal or objective was met, then determine actions to carry out if the objective was not met. For example, a program might want to meet a minimum criterion for student success on a licensing exam. If the criterion is not met, program changes that address areas where students were more likely to fail could be implemented and the impact of the changes then can be tracked in a future cycle.

A department might set minimum publication expectations for faculty, determine whether that expectation is met, and then make changes if it is not. For example, faculty might get changes in their course loads, the department might set up a subject pool for research, more productive senior faculty might be used to mentor younger faculty members, or a variety of other professional development activities could be undertaken. The ability to track these kinds of changes and interventions is facilitated through technology by having a central location in a database where the process can be made public. Such a system can also be advantageous for accreditation because almost all accreditation agencies look for evidence that institutions use data for program improvement.

However, the use of technology does not handle a large number of issues that are important elements to assessment systems. First, people still need to make the plans. Assessment plans that are not well thought out can create problems in implementation, data collection, and data analysis. Further, the nature of the data is really important. The data need to be reliable and valid and often the goal is provide data that are quantitative in nature so that change 
can be measured. However, there are some things do not lend themselves to easy quantification and most individuals who work as university professors have little training in what it means to state that a measure is reliable and valid, never mind going through a process to validate a measure.

Along with assessment for continuous improvement, there are assessments that are done for accountability purposes. Technology increases the reach of accountability measures. The ability to tag the teacher's training program in the data base of student test scores shows that the reach for accountability data can extend well beyond graduation rates, and success on professional tests. It can reach into the on-the-job success of candidates. Modern information technology makes such analyses possible with very little effort other than entering a field in a database.

So with all of these changes and the emphasis on accountability, what impacts have there been on faculty, students, and administrators in higher education? How have these different groups been influenced by the new technologies associated with assessment and accountability in higher education? Below are some issues related to accountability and assessment systems that may influence how people interact with them.

First, there is a need to consider how such systems fit into the existing work that people do. Another issue that plays a role is that educational institutions often do not view themselves like business organizations. The model taken from business does not always easily fit educational institutions, especially public institutions. What also may be problematic for implementing systems designed in the business world is that faculty enter academia with a view that the "Academy" does not operate like the business world. Most enjoy the flexibility, freedom, and creativity of working in an institution of higher education. An accountability system that may open up their work to scrutiny could be perceived as threatening that autonomy.

Another disadvantage that may limit the applicability of business-based quality improvement systems are the organizational structures of universities. For instance, the concept of tenure limits changes that can be made in personnel that might be warranted based on assessment data. This is not to say that improvement plans are a bad idea or that no changes can be made, but that differences in organizational structure may limit how these more business oriented models can apply.

\section{ASSESSMENT MEANING AND BURDEN IN INSTITUTIONAL ASSESSMENT SYSTEMS}

As noted earlier, one impact of new assessment systems is that they may provide more actual work. Faculty need to learn to use the technology and sometimes add to their grading. They may change how they work. If assessment planning works right, it can serve as a way of improving performance of the individual students, faculty members, and the organization. If it is perceived as the "make me more work more when I do not have any spare time already plan" rather than the plan for continuous improvement, there will be problems with buy in and acceptance. What potential concerns like this suggest is that the meaning of assessments to those involved in giving them is crucial to their success. Assessments have within them many layers of meaning to people who are involved in receiving, giving, and mandating them.

One of the difficulties in implementing a system of continuous improvement is that there is a need for people to perceive the system in a constructive way rather than as a personal indictment of their competency as a professional. As Argyris (1991) points out in his analysis of high level consultants, people who are generally very successful, often have difficulties dealing with critical analysis of their work. Just like high level consultants, university faculty members have been at least successful enough in their field to get a doctoral level degree.

Hence, they may have a difficult time accepting an institutional assessment system that is often designed by others to point out what they would perceive as purported flaws their work. Assessment systems involve power relations between people, and their meaning to people can have a great impact on how they are perceived (Simola \& Rhinne, 2008; Van Haneghan, 2009). For example, assessment systems mandated by accreditation agencies hold power over an institution's ability to operate on many levels, and hence, investments in meeting standards are important to university administrations. As noted earlier, this focus on meeting accreditation may threaten some faculty members who view it as taking away their academic freedom and disrespecting their expertise. On the other hand, as Van Haneghan (2008) points out, the system can be viewed in a positive light as a system for continuous improvement that can only enhance one's abilities as a faculty member and improve the programs that faculty are part of at their institution.

Not only are issues of the meaning of institutional assessment multifaceted for faculty, but students as well. Luyegu (2009) examined the implementation of an electronic portfolio system set up to assess state teacher education standards in a college of education. She found some confusion surrounding the system. Some students did not understand its purpose, and other students, like faculty members, felt that the expense and burden of the system was thrust upon them in an already busy curriculum. Van Haneghan (2008) coined the term "assessment burden" to describe how people perceive assessment systems. Assessment burden is a complex notion that assessments or systems of assessment are perceived as burdensome.

Assessments can be seen as burdensome when, as noted above, such systems are viewed as a threat. However, there are legitimate aspects of assessment systems that can create burden. For example, the working memory load (Sweller, 2006) associated with understanding the results of assessments, or figuring out a complex scoring system add legitimately to the work load of faculty members. Likewise, 
students who have to deal with a complex electronic portfolio system may be overwhelmed with understanding it.

Technology serves as a double-edged sword in that it can lessen the legitimate burden associated with assessment and accountability. On the other hand, it can also create burden because of its power as a data collection tool. Just because data can be collected on something does not mean it always should or need be collected.

Another issue that arises in considering assessment systems is that institutions of higher education are often have a balance the needs and wants of multiple accrediting agencies and regulators. For example, a college of education will have to deal with NCATE, state departments, professional specialty organizations, and regional accreditation agencies. All of these groups may have interests in an assessment system that addresses their standards. The unit has to coordinate all of these different standards into an assessment system. Sometimes that means duplication effort or setting up separate assessments that add further to the burden of assessment and evaluation.

\section{FINDING BALANCE}

As can be seen, technology has brought both exciting advances in assessment technologies that allow instructors and institutions to assess more accurately, more efficiently, and in new ways. However, with the power of new technologies comes the possibility of unintended consequences that are not always positive. The impacts of technology range from changing classroom assessments to creating very complex systems of assessments for evaluating programs and institutions. These complex systems can create assessment burden for faculty and institutions. Assessment and evaluation can create positive influences on students, faculty, and institutions. The goal is to find the right balance so that assessment systems can improve student performance and help programs and institutions continue to improve.

\section{REFERENCES}

[1] Argyris, C. (2004). Reflection and beyond in research on organizational Learning. Management Learning, 35(4), 507-509.

[2] Bransford, J. D., Brown, A. L., \& Cocking, R. (1999). How people learn: Brain, mind, experience, and school. Washington, DC: National Academy Press.

[3] Campbell, J., \& Mayer, R. E. (2009). Questioning as an instructional method: Does it affect learning from lectures? Applied Cognitive Psychology, 23, 747-759.

[4] Kuh, G. D., Kinzie, J., Schuh, J. H., \& Whitt, E. J. (2005). Student success in college: Creating conditions that matter. New York: Jossey-Bass.

[5] Lane, S., \& Stone, C. A. (2006). Performance assessment. In Brennan, R. L. (Ed.), Educational Measurement (4th ed., pp. 387-431). Westport, CT: Praeger. 